\title{
Revealing forerunners on Envisat's wave mode ASAR using the Global Seismic Network
}

\author{
R. Husson, ${ }^{1}$ F. Ardhuin, ${ }^{2}$ F. Collard, ${ }^{1}$ B. Chapron, ${ }^{2}$ and A. Balanche ${ }^{2}$ \\ Received 9 May 2012; revised 26 June 2012; accepted 26 June 2012; published 10 August 2012.
}

[1] Swells radiating across ocean basins are fingerprints of the large ocean storms that generated them, which are otherwise poorly observed. Here we analyze the signature of one swell event in the seismic noise recorded all around the Pacific and we show that it is a natural complement to the global coverage provided by the Synthetic Aperture Radar wave mode data from ENVISAT. In particular the seismic stations are much more sensitive to low frequency and amplitude signals than buoys and SAR, capturing swell forerunners a couple of days before they can be detected from space or in situ data. This information helps detect in the SAR measurements the presence of very long swell, with periods of $22 \mathrm{~s}$ in our case example, that were otherwise excluded. Citation: Husson, R., F. Ardhuin, F. Collard, B. Chapron, and A. Balanche (2012), Revealing forerunners on Envisat's wave mode ASAR using the Global Seismic Network, Geophys. Res. Lett., 39, L15609, doi:10.1029/2012GL052334.

\section{Introduction}

[2] Waves with periods larger than $13 \mathrm{~s}$ are routinely observed to propagate all the way across ocean basins from the area of high winds that generated them [Gain, 1918; Darbyshire, 1952; Munk et al., 1963; Young, 1999]. These swells are today still poorly predicted [Ardhuin et al., 2010] in spite of a better knowledge of their dissipation [Ardhuin et al., 2009]. Indeed, these long swells radiate from the most intense and long-lived storms, which are still poorly observed. There is thus a clear need for more swell observations, be it for navigation safety in coastal areas, or a better understanding of air-sea fluxes at low winds, in particular in the tropics [e.g., Edson et al., 2007]. In order to complement the sparse and spectrally limited coverage provided by satellite altimeters and space-borne Synthetic Aperture Radars, and the very few in situ measurement by buoys, especially in the Southern Hemisphere, we wish to advocate the potential complementarity use of seismic noise records from the Global Seismic Network.

[3] Indeed, the strongest source of seismic noise are the hydrodynamic interactions of waves with nearly equal periods and nearly opposite directions which leads to a fastpropagating pressure signal that generates noise, in particular seismic Rayleigh waves [e.g., Hasselmann, 1963]. This explains why the dominant recorded seismic noise has

\footnotetext{
${ }^{1}$ Collecte Localisation Satellites, Plouzané, France.

${ }^{2}$ IFREMER, Plouzané, France.
}

Corresponding author: R. Husson, Collecte Localisation Satellites, Bâtiment le Ponant, Avenue la Pérouse, F-29280 Plouzané CEDEX, France. (rhusson@cls.fr)

C 2012. American Geophysical Union. All Rights Reserved. 0094-8276/12/2012GL052334 periods that are half of that of the interacting wave trains [Bernard, 1941]. As a result, important noise sources are associated with sea states that contain a significant amount of energy radiating at the same frequency and in opposite directions. For seismic periods larger than $8 \mathrm{~s}$, corresponding to ocean waves with periods larger than $16 \mathrm{~s}$, this is most often the result of wave reflection from the shoreline [Haubrich et al., 1963; Bromirski et al., 1999; Ardhuin et al., 2011b].

[4] Only occasionally the noise recorded on land at these long periods is dominated by the interaction of swell from a remote storm with the local wind sea or another swell [Zopf et al., 1976; Kedar et al., 2008; Ardhuin et al., 2011b, 2012] even though it can be persistent when considering shorter periods [Stehly et al., 2009; Kedar, 2011]. The seismic noise record from a land-based station thus provide a very clear detection, that is generally unambiguous, of the swell arriving at the nearest shoreline.

[5] The seismic source is actually dominated by contributions from water depths larger than $1000 \mathrm{~m}$, due to the seismic generation process [Longuet-Higgins, 1950], over regions that typically span hundreds of kilometers, or even more for mid-oceanic islands [Ardhuin et al., 2011b]. However, the wave interaction only occurs when the incident swells interact with the reflected swells. Because the group velocity on a typical shelf is not very different from that in deep water, the maximum of noise generation should indeed occur when the incident swell energy is maximum right at the shoreline.

[6] Waves heights and periods, and the full frequency spectrum, may then be estimated from seismic records [Bromirski et al., 1999; Ardhuin et al., 2010]. This should even be easier when applied exclusively to long period swells because there is little contribution of sources not associated to shoreline reflection [Ardhuin et al., 2012]. Besides, the swells have a distinctive time-evolution of the frequency spectrum with a gradual decrease of the peak period over a few days. This was particularly well demonstrated by Barruol et al. [2006], who analyzed swells from seismic stations in Polynesia. These stations are now analyzed in real time for local marine forecasts and high surf advisories. The existing long record of seismic observations, together with the good coverage of the Global Seismic Network in both hemispheres is a compelling argument for generalizing this quantitative use of seismic data, and blending it with remote sensing data and numerical wave models.

[7] Collard et al. [2009] already highlighted the ability to monitor ocean swell fields from space as they propagate through ocean basins. Taking the example of a powerful ocean storm that peaked on April 11th, 2008 South-East of New-Zealand, we take advantage of the synoptic view of the swell propagating across the ocean basin provided by the 


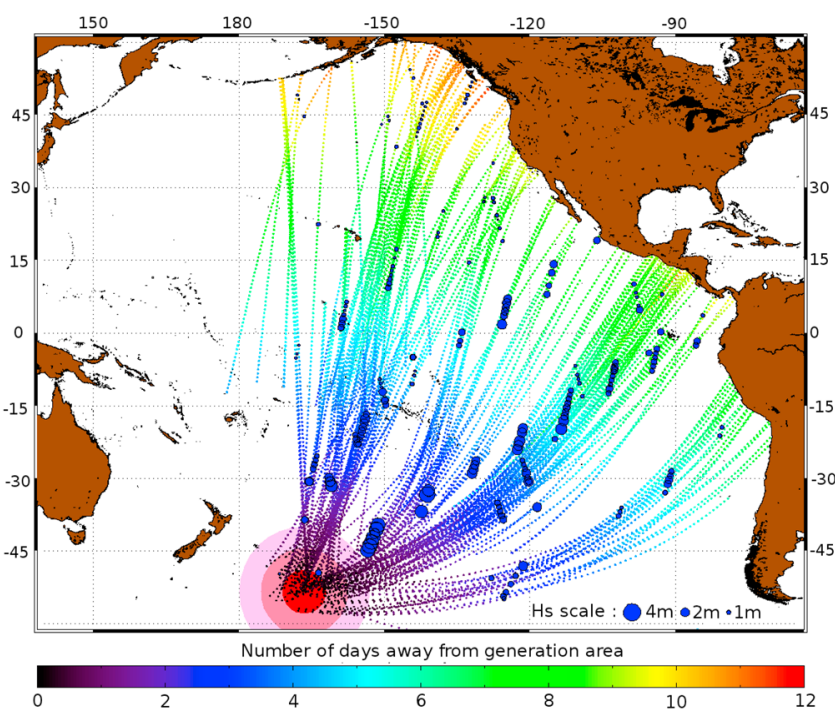

Figure 1. Trajectories of all the swell observations given by the SAR wave mode and associated to the storm of 11 April 2008, South-East of New-Zealand. The generation region is symbolized by a red disk and the color along the trajectories indicates the days of travel since generation. Blue disks are placed at observation locations. Their size indicates the significant swell height at this moment.

SAR. The analysis of SAR data is described in section 2, leading to the estimation of swell parameters time series in the deep ocean, in the vicinity of each GSN stations. Both seismic and SAR data are compared in section 3.

\section{Analysis of SAR Data}

[8] SAR instruments can be used to image the propagation of an ocean swell field [e.g., Holt et al., 1998; Heimbach and Hasselmann, 2000]. Latest quality assessment of the SAR wave measurements indicates estimations of the peak period and direction with root mean square errors of 1.07 seconds and $20^{\circ}$, respectively [Collard et al., 2009]. Yet, these swell measurements are still limited to waves with peak period less than $18 \mathrm{~s}$ and significant wave height larger than $30 \mathrm{~cm}$. Therefore, the longest period swells that propagate ahead of the most energetic swell components, called forerunners by Munk [1947], are excluded from the SAR present algorithm.

[9] Using the methods proposed by Collard et al. [2009], the swell event is reconstructed gathering backward propagated swell observations that converge in space and time to the generation region. Over deep ocean and away from islands, the emanating swell field is defined by that group of swell observations propagated on from this area, using linear propagation theory. Figure 1 represents the trajectory of all the swell observations associated to the April 2008 storm.

[10] Numerical wave hindcasts provided by the IOWAGA project [Ardhuin et al., 2010, 2011a] give a total significant wave height reaching $14 \mathrm{~m}$, when using ECMWF analysis winds, with mean wave direction oriented to the North-East. The swell field then swept all over the East Pacific for the next two weeks. Buoys located in Alaska, more than $10000 \mathrm{~km}$ away from the storm source, recorded swell heights around $0.4 \mathrm{~m}$.
[11] The SAR dataset can be used to estimate swell parameters time series at any given location. The estimated swell peak direction is given by the azimuth to the generation region. The swell peak period is estimated for any chosen time by fitting a second-order polynomial function of the distance to the source and distance to the swell field main direction of propagation. This fit gives more weight to observations with higher confidence. This 2 nd order function reproduces the spatial distribution of wavelengths better than a linear function. Indeed, wave generated by long-lived and/or fast moving storm events have been proven to leave the storm generation region at different times and location depending on their wavelength [Delpey et al., 2010].

[12] Using this principle, wave peak period and direction evolution is estimated at various locations. In our example, this is first done at the buoy 'Stratus' (WMO number 32012), maintained by the Woods Hole Oceanographic Institution (WHOI) and moored off the coast of Peru in $4440 \mathrm{~m}$ of water. The same processing is then applied at ocean locations close to land-based seismometers. In that case the resulting data is shifted in time by the propagation time, estimated from linear theory, between the chosen oceanic point and the coast, and the estimated frequencies are multiplied by two for a direct comparison with the seismic data.

\section{Complementarity of SAR and Seismic Data}

[13] Seismic noise observations overlaid with results from the SAR analysis are presented in Figure 2a. They show wave spectra time series integrated over directions for buoy Stratus and seismic noise spectra time series of stations RPN (Rapa Nui, Easter Island), KIP (Kipapa, Hawaii), NNA (Nana, Lima, Peru), UNM (Mexico City, Mexico) and JTS (Las Juntas de Abangares, Costa Rica). Their position is indicated in Figure 2b.

[14] Comparison with the Stratus buoy indicates that the swell arrived within 12 hours of our estimate based on SAR data. The swell arrives from South-West and in four days, the frequency where the energy is maximum gradually increases from 0.055 to $0.08 \mathrm{~Hz}$. After partitioning the ocean wave spectra, the peak period and direction estimated by the SAR give root mean square errors of 0.34 seconds and $23^{\circ}$, with bias of -0.01 seconds and $-3.6^{\circ}$, respectively.

[15] As it is well known [Haubrich et al., 1963], the swell frequency is expected to increase linearly in time and so does its seismic noise signature at primary and secondary, i.e., double, frequency. Here, the secondary frequency increase is observed at every seismic stations and can be followed up to $0.14 \mathrm{~Hz}$, corresponding to $0.07 \mathrm{~Hz}$ ocean waves. The level of this signal compared to other noise sources is particularly high at continental stations compared to island stations thanks to the larger shoreline extension that intercepts the incoming wave flux.

[16] The fact that the noise is generated by coastal reflection is confirmed by the presence of noise at primary frequency [Haubrich et al., 1963], which here is shown only for JTS. This signal is specific to shallow waters and results from the interaction of ocean swell with a shoaling ocean bottom [Hasselmann, 1963].

[17] Compared to the buoy and seismic-detected swells, the SAR estimations of swell frequencies are very consistent. 
SAR data provides a record of swell frequencies from 0.06 to $0.08 \mathrm{~Hz}$ while seismic noise data corresponds to 0.04 to $0.07 \mathrm{~Hz}$. Seismic noise data, as already noted by Haubrich et al. [1963], offers a nice extension to low frequencies of

(a)
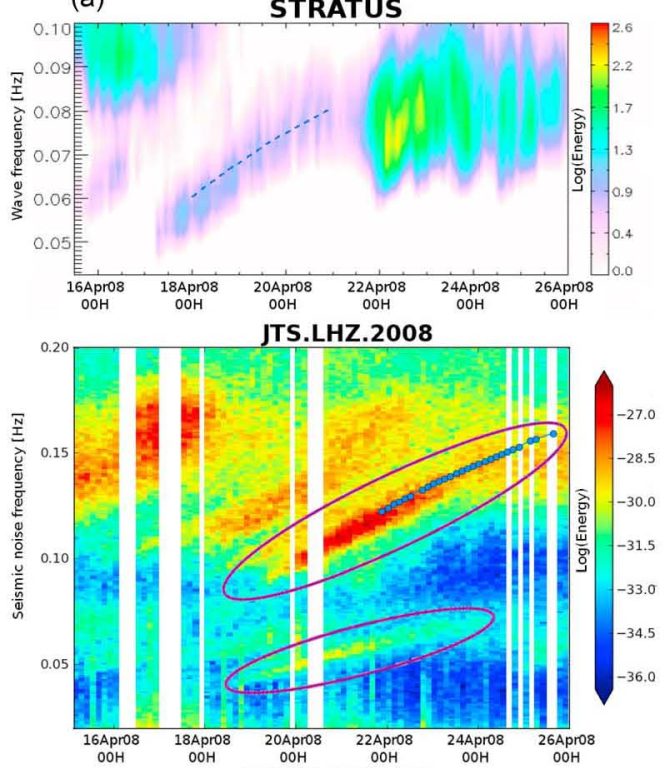

UNM.LHZ.2008

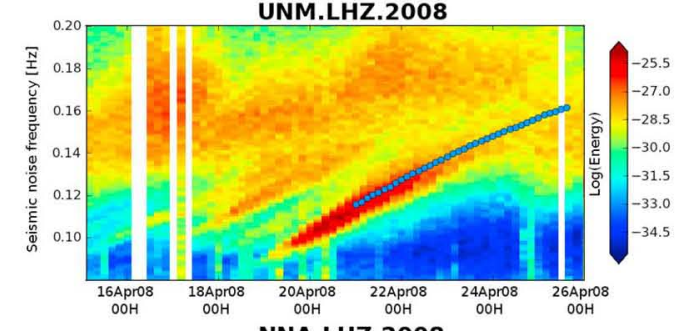

NNA.LHZ.2008
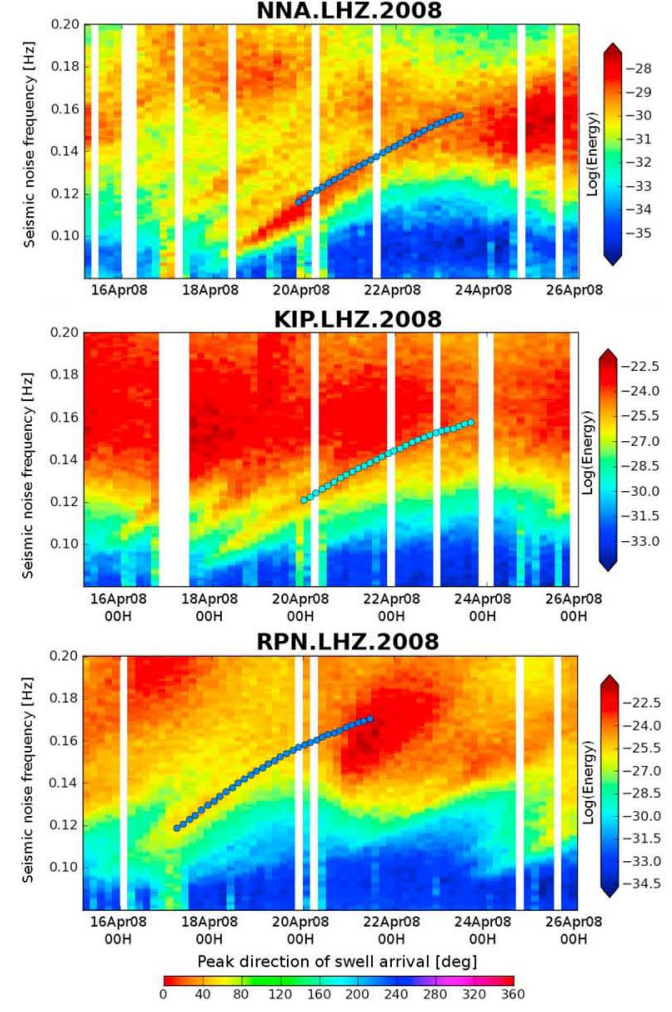

conventional wave measurements at a fixed point with pressure recorders. Here we show that this is even more true for SAR data excluding very long swell, usually around $17 \mathrm{~s}$, from its measurements. In the present example, the

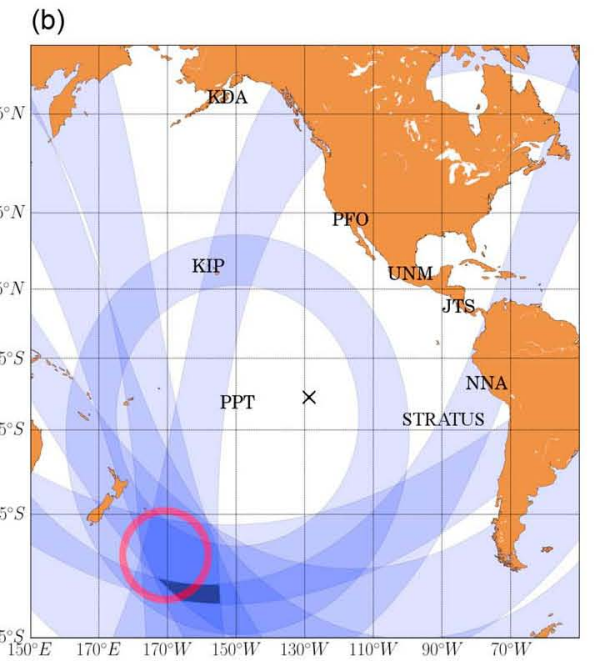

Figure 2 


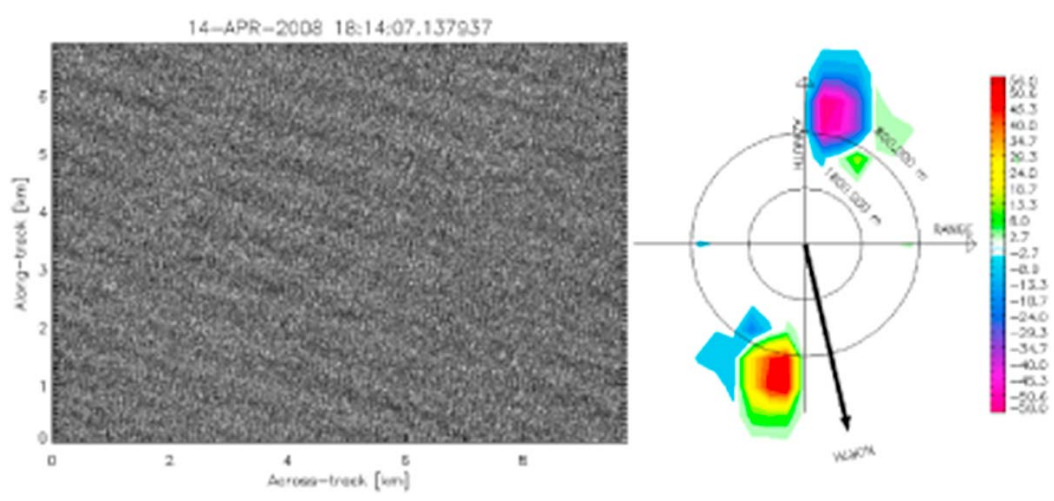

Figure 3. (left) SAR ocean image exhibiting very long swell as acquired by ASAR instrument on-board ENVISAT 3 days after the storm generation and (right) associated imaginary spectrum, weighted by the energy spectrum indicating the presence of a $750 \mathrm{~m}$ swell propagating in North-East direction. The SAR measurement geographical location is indicated in Figure $2 \mathrm{~b}$ by a black cross.

frequency of the longest buoy-detected swell is $0.055 \mathrm{~Hz}$ and only the seismic stations can measure $0.04 \mathrm{~Hz}$ swell.

[18] The full Global Seismic Network data can also be used alone to triangulate the storm source location and time. For each seismic station, the double frequency ridge slope is automatically estimated by maximizing the energy encountered along a straight line placed on the ridge. Then, the distance to the expected storm source is determined according to equation (1).

$$
D=\frac{g}{8 \pi}\left(\frac{d f_{s}}{d t}\right)^{-1}
$$

where $f_{s}$ is the seismic noise frequency; the the of arrival; $\mathrm{g}$, the earth gravity and $\mathrm{D}$, the seismic station distance to the expected storm source.

[19] As evidenced in Figure 2b, the seismic source location based on longer period waves and the SAR source location are in general agreement.

[20] Once the storm source location is found and the presence of very long swell is proven by seismic noise measurements, its expected arrival time is calculated using linear theory. Using this information, at appropriate times and locations, we look for this long swell signature on the SAR image spectra directly, as opposed to the SAR ocean spectra. Indeed, for such waves, under light to moderate wind speeds, a quasi-linear imaging mechanism is a valid assumption [Krogstad, 1992]. This way, swell with peak frequency equal to $0.045 \mathrm{~Hz}$ is detected 3 days after the storm in the South Pacific Ocean, as shown in Figure 3. The induced very long scale modulation is visible on the SAR image, depicting a long wave group.

[21] In the past, as no evidence of the presence of very long waves in the ocean wave spectrum could be easily and frequently provided, associated low frequency signatures were flagged in the SAR image spectra and excluded from the ocean wave spectrum inversion. Now, taking these signals into account dramatically increases the frequency range of observable swell using the SAR instrument, which is almost doubled.

[22] Since long swell travels faster than the one presently detected by the SAR, this potential improvement would enable us forecast the swell arrival several days ahead. For operational early-warning applications, one would have to use data from seismic stations nearby the storm region or, alternatively, numerical wave models. Though, the peak period information they provide can be significantly underestimated [Hanson et al., 2009] and they fail to capture the early arrival of waves at low frequencies [Wingeart, 2001]. Also, better SAR ocean swell monitoring can benefit to numerical wave models assimilating this information, thereby improving their significant swell height estimation which are largely under-estimated for long swell [Hanson et al., 2009].

[23] The proof of physical presence of very long swell provided by the seismic noise is a necessary information for the retrieval of the swell geophysical parameters given by the SAR. Indeed, modulation of the low frequency spectrum by phenomena unrelated to long swell like low wind area may be miscellaneously attributed. However, the previously described scheme going through the identification of a

\footnotetext{
Figure 2. (a) Spectra time series for buoy 'Stratus' (lon: -85.384 , lat: -19.616) and seismic stations KIP, RPN, KIP, NNA, UNM and JTS in mid-April 2008. For JTS, the primary signal is shown as well and both the secondary and the primary signals are circled in dark magenta. SAR swell parameters estimation at secondary frequency is overlaid in colored disk indicating north-eastern propagation. Main seismic events have been filtered out. (b) Location of the expected storm source from two independent instruments: the SAR wave mode products and seismic noise measurements. For each seismic station (UNM, PFO, KDA, PPT, JTS, NNA and KIP), a $1500 \mathrm{~km}$ wide blue disk is plotted, its radius being equal to the distance to the storm source estimated from the differential arrival time of the swell at the seismic station using seismic noise alone. The $1500 \mathrm{~km}$ width corresponds to the average accuracy of the distance estimation given by the automatic radius estimation. The storm source given by the SAR analysis is circled in red. The Stratus buoy location is also indicated and a black cross is placed at the location where the SAR observation shown in Figure 3 was acquired.
} 
massive swell event using SAR analysis, of the corresponding ridge-like structure in the seismic noise and estimation of longest present swell can easily be automated from the moment that we have access to the seismic noise data. Extending this approach to other years, a swell with a frequency of $0.04 \mathrm{~Hz}(24.7 \mathrm{~s})$ was detected using the SAR in the South Pacific Ocean in late August 2011.

[24] Finally, even though the imaging capability of extremely long swell is limited by the ground coverage of the ASAR wave mode, barely imaging an entire wave group, the extended $20 \times 20 \mathrm{~km}^{2}$ coverage of the future Sentinel-1 SAR mission compared to the $7 \times 10 \mathrm{~km}^{2}$ of ENVISAT will easily tackle this issue.

\section{Conclusion}

[25] The present study highlights ASAR wave mode capability to image very long swell whenever used together with seismic noise data from the Global Seismic Network for the observation of ocean swells. From all SAR swell observations after April 11th, 2008, a massive swell event that occurred South-East of New Zealand was reconstructed. Using the virtual buoy concept, the swell peak period and direction time series related to this event were estimated at various locations. First, they were compared to spectra given by Stratus moored buoy. In four days, the peak period slowly and linearly decreases from 17 to $12 \mathrm{~s}$. Peak period and direction estimations give root mean square errors of 0.34 seconds and $23^{\circ}$, respectively. Similarly, the swell signal recorded in the seismic noise by coastal and island stations was simulated. Comparison to seismic noise spectra indicate very good fit within their common period range, from 14 to $17 \mathrm{~s}$, demonstrating the capability of the SAR not only to provide both a global and a local view of the swell field propagation across an entire ocean basin but also its ability to reproduce its signal in seismic noise as measured by coastal stations. Thereby, ridges related to the same swell system for different seismic stations could be associated and the precise storm source of the longest swell triangulated.

[26] By default, forerunners are not detected by the SAR but seismic noise records reveal their presence when arriving to the coast. Then, looking at appropriate expected arrival time and location in open ocean, their signature is found in the SAR image spectra. Using this technique swell with periods up to $24.7 \mathrm{~s}$ were detected on SAR measurements. Their observability will even be improved by the future Sentinel-1 SAR mission extended ground coverage.

[27] The great sensitivity of seismometers to very long waves and their high frequency resolution of these phenomena compared to moored buoys is a tremendous asset for a better calibration and validation of SAR observations of long swell. Then, the other way around, the SAR may be used to calibrate the wave-to-seismic transfer function to contribute to the development capability of a global wave monitoring network.

[28] Acknowledgments. The Global Seismographic Network (GSN) is a cooperative scientific facility operated jointly by the Incorporated Research Institutions for Seismology (IRIS), the United States Geological Survey (USGS), and the National Science Foundation (NSF). The facilities of the IRIS Data Management System (DMS), and specifically the IRIS Data Management Center, were used for access to waveform and metadata required in this study. We particularly used data from the Geoscope, IRIS IDA and IRIS USGS networks whose contribution is gratefully acknowledged. SAR data were provided by the European Space Agency (ESA) and buoy data were kindly provided by Woods Hole Oceanographic institution (WHOI). This work is funded by the ANRT and CLS as part of R. H. PhD thesis. F. A. and A. B. were supported by ERC grant 240009 'IOWAGA'

[29] The Editor thanks two anonymous reviewers for assisting in the evaluation of this paper.

\section{References}

Ardhuin, F., B. Chapron, and F. Collard (2009), Observation of swell dissipation across oceans, Geophys. Res. Lett., 36, L06607, doi:10.1029/ 2008 GL037030.

Ardhuin, F., et al. (2010), Semi-empirical dissipation source functions for wind-wave models: Part I, Definition, calibration and validation, J. Phys. Oceanogr., 40(9), 1917-1941.

Ardhuin, F., J. Hanafin, Y. Quilfen, B. Chapron, P. Queffeulou, M. Obrebski, J. Sienkiewicz, and D. Vandemark (2011a), Calibration of the IOWAGA global wave hindcast (1991-2011) using ECMWF and CFSR winds, paper presented at 12th International Workshop of Wave Hindcasting and Forecasting, Environ. Can., Kohala Coast, Hawaii, 30 Oct. -4 Nov.

Ardhuin, F., E. Stutzmann, M. Schimmel, and A. Mangeney (2011b), Ocean wave sources of seismic noise, J. Geophys. Res., 116, C09004 doi:10.1029/2011JC006952.

Ardhuin, F., A. Balanche, E. Stutzmann, and M. Obrebski (2012), From seismic noise to ocean wave parameters: General methods and validation, J. Geophys. Res., 117, C05002, doi:10.1029/2011JC007449.

Barruol, G., D. Reymond, F. R. Fontaine, O. Hyvernaud, V. Maurer, and K. Maamaatuaiahutapu (2006), Characterizing swells in the southern Pacific from seismic and infrasonic noise analyses, Geophys. J. Int., 164, 516-542, doi:10.1111/j.1365-246X.2006.02871.x.

Bernard, P. (1941), Sur certaines proprietes de la boule etudiées a l'aide des enregistrements seismographiques, Bull. Inst. Oceanogr. Monaco, 800, $1-19$.

Bromirski, P. D., R. E. Flick, and N. Graham (1999), Ocean wave height determined from inland seismometer data: Implications for investigating wave climate changes in the NE Pacific, J. Geophys. Res., 104, 20,753-20,766.

Collard, F., F. Ardhuin, and B. Chapron (2009), Monitoring and analysis of ocean swell fields from space: New methods for routine observations, J. Geophys. Res., 114, C07023, doi:10.1029/2008JC005215.

Darbyshire, J. (1952), The generation of waves by wind, Proc. R. Soc. London, Ser. A, 215, 299-328.

Delpey, M. T., F. Ardhuin, F. Collard, and B. Chapron (2010), Space-time structure of long ocean swell fields, J. Geophys. Res., 115, C12037, doi:10.1029/2009JC005885.

Edson, J., et al. (2007), The coupled boundary layers and air-sea transfer experiment in low winds, Bull. Am. Meterol. Soc., 88(3), 341-356.

Gain, L. (1918), La prédiction des houles au maroc, Ann. Hydrogr., 65-75.

Hanson, J. L., B. A. Tracy, H. L. Tolman, and R. D. Scott (2009), Pacific hindcast performance of three numerical wave models, J. Atmos. Oceanic Technol., 26(8), 1614-1633.

Hasselmann, K. (1963), A statistical analysis of the generation of microseisms, Rev. Geophys., 1(2), 177-210.

Haubrich, R., W. Munk, and F. Snodgrass (1963), Comparative spectra of microseisms and swell, Bull. Seismol. Soc. Am., 53(1), 27-37.

Heimbach, P., and K. Hasselmann (2000), Development and application of satellite retrievals of ocean wave spectra, in Satellites, Oceanography, and Society, edited by D. Halpern et al., Elsevier Oceanogr. Ser., 63, 5-33.

Holt, B., A. K. Liu, D. W. Wang, A. Gnanadesikan, and H. S. Chen (1998), Tracking storm-generated waves in the northeast Pacific Ocean with ERS-1 synthetic aperture radar imagery and buoys, J. Geophys. Res., 103(C4), 7917-7929.

Kedar, S. (2011), Source distribution of ocean microseisms and implications for time-dependent noise tomography, C. R. Geosci., 343, 548-557.

Kedar, S., M. Longuet-Higgins, F. Webb, N. Graham, R. Clayton, and C. Jones (2008), The origin of deep ocean microseisms in the North Atlantic Ocean, Proc. R. Soc. A, 464(2091), 777-793, doi:10.1098/ rspa.2007.0277.

Krogstad, H. E. (1992), A simple derivation of hasselmann's nonlinear ocean-synthetic aperture radar transform, J. Geophys. Res., 97(C2), 2421-2425.

Longuet-Higgins, M. S. (1950), A theory of the origin of microseisms, Philos. Trans. R. Soc. London, Ser. A, 243(857), 1-35.

Munk, W. H. (1947), Tracking storms by forerunners of swell, J. Atmos. Sci., 4, 45-57.

Munk, W. H., G. R. Miller, F. E. Snodgrass, and N. F. Barber (1963), Directional recording of swell from distant storms, Philos. Trans. R. Soc. London, Ser. A, 255(1062), 505-584. 
Stehly, L., B. Fry, M. Campillo, N. M. Shapiro, J. Guilbert, L. Boschi, and D. Giardini (2009), Tomography of the Alpine region from observations of seismic ambient noise, Geophys. J. Int., 178(1), 338-350, doi:10.1111/j.1365-246X.2009.04132.x.

Wingeart, K. M. (2001), Validation of operational global wave prediction models with spectral buoy data, in Ocean Wave Measurement and Analysis, pp. 590-599, Am. Soc. of Civ. Eng., New York.
Young, I. R. (1999), Seasonal variability of the global ocean wind and wave climate, Int. J. Climatol., 19(9), 931-950.

Zopf, D. O., H. C. Creech, and W. H. Quinn (1976), The wavemeter: A land-based system for measuring nearshore ocean waves, Mar. Technol. Soc. J., 10(4), 19-25. 